This document is the Accepted Manuscript version of a Published Work that appeared in final form in Macromolecules, copyright (C) American Chemical Society after peer review and technical editing by publisher. To access the final edited and published work see https://dx.doi.org/10.1021/acs.macromol.6b02538

\title{
Using Pyrene Excimer Fluorescence to Probe the Interactions between Viscosity Index Improvers and Waxes Present in
}

\section{Automotive Oil}

\author{
Solmaz Pirouz, Jean Duhamel* \\ Waterloo Institute for Nanotechnology, Institute for Polymer Research, Department of \\ Chemistry, University of Waterloo, Waterloo, ON N2L 3G1, Canada
}

Sheng Jiang, Akhilesh Duggal ${ }^{\S}$

Afton Chemical Corporation, 500 Spring Street, Richmond, VA 23219, USA

* To whom correspondence should be addressed.

§ Current address: ExxonMobil Corporation, 22777 Springwoods Village Parkway, Spring, TX 77389 


\section{ABSTRACT}

A new methodology based on pyrene excimer fluorescence (PEF) was applied to quantitatively measure the actual level of intermolecular association between ethylene-propylene (EP) copolymers in toluene in the presence of wax, an intrinsic component of engine oils. EP copolymers are commonly used as viscosity index improvers (VIIs) in engine oils. Unfortunately waxes in engine oils thicken the oil and are suspected of associating with VIIs at low temperature. In this study, four EP copolymers were maleated to yield EP-MA and then fluorescently labeled with 1-pyrenemethylamine to yield Py-EP. Successful maleation and pyrene labeling were confirmed by Fourier transform infrared (FTIR) and UV-Vis absorption spectroscopy. The solution behaviour of the EP copolymers in the presence of wax was characterized by PEF, which was used to quantitatively measure the molar fraction of intermolecular interactions $\left(f_{\text {inter }}\right)$ between EP copolymers in the absence or presence of wax. The fraction $f_{\text {inter }}$ was determined through the analysis of the fluorescence spectra of the Py-EP solutions acquired as a function of temperature. Upon excitation, the Py-EP solutions generated excimer upon encounter between an excited and a ground-state pyrene. The ratio of the excimer fluorescence intensity $\left(I_{\mathrm{E}}\right)$ over that of the monomer ( $\left.I_{\mathrm{M}}\right)$ yielded the $I_{\mathrm{E}} / I_{\mathrm{M}}$ ratio which was employed to determine $f_{\text {inter. }}$. Plots of $f_{\text {inter }}$ as a function of temperature provided a description of the solution behaviour of a given VII with or without wax present in solution. The results of this study indicate that wax in solution binds onto EP copolymers dissolved in toluene, which increases macromolecular associations as reflected by an increase in $f_{\text {inter. }}$ The formation of microcrystals between semicrystalline EP copolymers however induces strong polymer-polymer interactions that result in the dissociation of the wax from the polymers. 


\section{INTRODUCTION}

An engine oil formulation is usually a mixture of base oils and oil-additives. Oil-additives enhance the base oil lubricating properties and the base oil must maintain proper solvency of these oil additives during the operation of the engine. Dispersants, detergents, viscosity index improvers (VIIs), pour point depressants (PPDs), and antiwear and antioxidant agents are different types of oil additives typically present in an engine oil. ${ }^{1}$ VIIs are long chain, high molecular weight polymers used to reduce the decrease in viscosity of the base oil upon increasing temperature without excessively increasing the viscosity of the oil at lower temperatures. ${ }^{2-4}$ This feature becomes particularly important in countries with wide temperature differentials between engine start up, with start up temperatures being as low as $-40{ }^{\circ} \mathrm{C}$ during the North American winter, and the normal operating temperature of the engine which reaches $+200{ }^{\circ} \mathrm{C}$. Consequently, VIIs are essential components of an engine oil to enhance the oil efficiency and durability while providing maximum engine protection. The performance of the VII depends on the polymer solubility, its interactions with other chemicals found in the oil, and its shear and oxidation resistance. 5,6

The best known VIIs are polymethacrylates, polyisoprene-polybutadiene-polyisoprene star polymers, ethylene-propylene (EP) copolymers, and hydrogenated styrene-diene copolymers. ${ }^{4,7-}$ ${ }^{10}$ As they are the focus of this study and since they constitute an important family of VIIs, EP copolymers are described in more details hereafter. EP copolymers were first introduced as VIIs in the late 1960s. ${ }^{11}$ The ethylene-to-propylene molar ratio defines the quality of a given EP copolymer as a VII. ${ }^{7,11}$ The presence of long ethylene sequences in EP copolymers induces polymer crystallinity that changes the hydrodynamic volume of the polymer coil in a way that yields desirable lubrication properties for an engine oil as a function of temperature. But polymer sequences with higher ethylene contents are also expected to interact strongly with wax present in 
the engine oil at very low temperatures. ${ }^{12}$ The interactions between wax and EP copolymers are expected to affect $V_{\mathrm{h}}$ of the EP copolymers coil, and thus the viscosity of the EP copolymer solution. Furthermore, the interactions between wax and EP copolymers might be further enhanced at temperatures between -20 and $+20^{\circ} \mathrm{C}$ where semicrystalline $\mathrm{EP}$ copolymers with high ethylene contents are reported to undergo a massive decrease in $V_{\mathrm{h}}$ due to the formation of microcrystals in solution. ${ }^{3,4}$ Even though most of the wax is removed during dewaxing, a small amount of wax remains in the oil. These waxes are composed of long chain hydrocarbons which vary in molecular weight and composition. ${ }^{13,14}$ Consequently the study of the effect that the presence of wax has on the interactions taking place between EP copolymers as a function of temperature in a temperature range between -30 and $+30{ }^{\circ} \mathrm{C}$ is of high interest to the oil-additive industry.

Intermolecular association between macromolecules is typically investigated by fluorescence resonance energy transfer (FRET) $)^{2,15,16,17}$ and pyrene excimer fluorescence (PEF). ${ }^{2}$ But a quantitative measure of the molar fraction $\left(f_{\text {inter }}\right)$ of macromolecules involved in intermolecular associations is only provided when PEF is used. ${ }^{18,19}$ As was shown in a previous study, ${ }^{19} f_{\text {inter }}$ can be determined in a simple and straightforward manner from the ratio $I_{\mathrm{E}} / I_{\mathrm{M}}$ of the fluorescence intensity of the excimer $\left(I_{\mathrm{E}}\right)$ over that of the monomer $\left(I_{\mathrm{M}}\right)$ obtained from the fluorescence spectrum of pyrene-labeled macromolecules (PyLMs). Since the fluorescence intensity ratio $I_{\mathrm{E}} / I_{\mathrm{M}}$ is directly proportional to the local pyrene concentration $[P y]_{\text {loc }}$ experienced by an excited pyrene surrounded by ground-state pyrenes covalently attached onto a macromolecule, ${ }^{20-24}$ an increase in $I_{\mathrm{E}} / I_{\mathrm{M}}$ due to intermolecular interactions reflects an increase in $[P y]_{\text {loc }}$ which can be taken advantage of to measure $f_{\text {inter. }}$ The ability to measure the fraction $f_{\text {inter }}$ provides a novel and powerful analytical tool that allows one to probe macromolecular interactions in solution under different conditions. 
Such procedures involving PyLMs become particularly important within the context of oil formulations which, as described earlier, are complex mixtures of varied chemicals which all have a specific purpose and that are each expected to perform optimally in oil independently of all others. As long as the fluorescence of the PyLM can be isolated from that of the other non- or weakly emissive chemicals, the behaviour of the PyLM can be investigated. Under such conditions, the determination of $f_{\text {inter }}$ for a PyLM of interest in the presence or absence of other chemicals enables one to assess whether these other chemicals affect the behavior of the PyLM. These appealing features were taken advantage of in the present study to investigate how the presence of wax affects the $f_{\text {inter }}-v s-T$ profiles of solutions of EP copolymers used as VIIs and having different chemical compositions, and thus different levels of crystallinity.

\section{EXPERIMENTAL}

Chemicals. Acetone (HPLC grade), dodecane (anhydrous, 99\%), toluene (HPLC, 99.9\%), biphenyl (99\%), 1,1,2,2-tetrachloroethane- $\mathrm{d}_{2}$ (TCE- $\mathrm{d}_{2}$ ), methyl ethyl ketone (MEK, 99.5\%), maleic anhydride (98\%), 1-pyrenemethylamine hydrochloride $\left(\mathrm{PyCH}_{2} \mathrm{NH}_{2} \mathrm{HCL}, 95 \%\right)$, and tertbutyl peroxide $(98 \%)$ were purchased from Sigma-Aldrich and were employed without further purification. Four EP copolymers, two amorphous polymers with an ethylene content of $60 \mathrm{~mol} \%$ and two semicrystalline polymers with an ethylene content of $78 \mathrm{~mol} \%$, and an engine oil wax were supplied by Afton.

Carbon Nuclear Magnetic Resonance $\left({ }^{13} \mathrm{C}\right.$ NMR). ${ }^{13} \mathrm{C}$ NMR was used to calculate the molar ethylene content of the EP copolymers. ${ }^{25}$ To acquire the ${ }^{13} \mathrm{C}$ NMR spectra of the EP copolymers at $120^{\circ} \mathrm{C}$, a Bruker $500 \mathrm{MHz}$ high resolution NMR spectrometer was employed. ${ }^{26} \mathrm{EP}$ copolymers 
$(0.14 \mathrm{~g})$ were dissolved in TCE- $\mathrm{d}_{2}$. Before acquiring each NMR spectrum, the solution in the NMR tube was homogenized by placing it in a heating block at $120{ }^{\circ} \mathrm{C}$ for a minimum of $4 \mathrm{hrs}$.

Fourier Transform Infrared (FTIR). A Bruker Tensor 27 FTIR spectrophotometer was used to obtain all FTIR spectra. To produce a thin polymer film on a NaCl FTIR plate, a few drops of polymer solution in toluene were deposited onto the cell and the solvent was then evaporated under a stream of nitrogen. All samples had an absorbance of less than unity to optimize the signal-tonoise ratio.

Differential Scanning Calorimeter (DSC). The melting point $\left(T_{\mathrm{m}}\right)$ and enthalpy $(\Delta H)$ of the EP copolymers were determined using DSC with a TA Q2000 calorimeter with temperature scanning rate of $10{ }^{\circ} \mathrm{C} / \mathrm{min}$. Each sample was first heated from -30 to $+200{ }^{\circ} \mathrm{C}$ followed by cooling from +200 to $-30{ }^{\circ} \mathrm{C}$, and finally heating from -30 to $+200{ }^{\circ} \mathrm{C}$.

Oil Dewaxing. Engine oil lubricants are formulated from a range of base oils and additives. The base oil is mostly produced by the refining of crude oil. The American Petroleum Institute (API) has categorized base oils into five categories as shown in Table 1. Oils from Group I - III are derived from petroleum crude oil and are ranked according to their sulfur and saturated alkane content and their viscosity index (VI). Group IV oils are synthesized from $\alpha$-olefins and are thus sulfur-free and fully saturated while Group V oils represent all other types of oils that do not belong to the Group I - IV oils.

A group II base oil was used in this study. The base oil (5 wt\%) was mixed with methyl ethyl ketone (MEK, $95 \mathrm{wt} \%$ ) at room temperature until an homogenous solution was obtained. The solution was placed in a $-20{ }^{\circ} \mathrm{C}$ freezer for $24 \mathrm{hrs}$ to allow precipitation of the wax. The wax was separated by suction filtration with a filter paper and application of vacuum. The final product was dried in a vacuum oven at $70{ }^{\circ} \mathrm{C}$ for $2 \mathrm{hrs}$. 
Table 1. American Petroleum Institute (API) base oil categories. ${ }^{27}$

\begin{tabular}{|c|c|c|c|}
\hline Group & Sulfur (wt\%) & Saturates (wt $\%)$ & $\begin{array}{c}\text { Viscosity Index } \\
\text { (VI) }\end{array}$ \\
\hline I & $>0.03$ & $<90$ & $80-120$ \\
\hline II & $>0.03$ & $>90$ & $80-120$ \\
\hline III & $>0.03$ & $>90$ & $>120$ \\
\hline IV & \multicolumn{2}{|c|}{ Polyalphaolefins Synthetic Lubricants } \\
\hline V & \multicolumn{2}{|c|}{ All base oils not included above } \\
\hline
\end{tabular}

The molecular weight distribution (MWD) of the wax was characterized by gel permeation chromatography (GPC). A $1 \mathrm{mg} / \mathrm{mL}$ wax solution in THF was injected into a PolyAnalytik SupeRes PAS-101 oligomer column with a 1.5K exclusion limit fitted onto a Viscotek VE 2001 GPC equipped with a TDA 305 triple detector array and a 2600 UV detector, using THF as the mobile phase. Due to the low molecular weight of the wax, only the detectors for differential refractive index (DRI) and UV Vis absorbance set at $245 \mathrm{~nm}$ were used to determine the MWD of wax. The column was maintained at a temperature of $35^{\circ} \mathrm{C}$ and the flow rate was $1 \mathrm{~mL} \cdot \mathrm{min}^{-1}$. The instrument was calibrated with polystyrene standards. Based on this calibration, wax had an apparent $M_{\mathrm{n}}$ and PDI value of 600 g.mol ${ }^{-1}$ and 1.25, respectively (see Figure S5). Its absorption spectrum is shown in Figure S6. Its fluorescence spectrum is presented in Figure 3.

Steady-State Fluorescence. Acquisition of the fluorescence spectra of the pyrene-labeled EP copolymers (Py-EPs) was conducted on a Photon Technology International (PTI) LS-100 steadystate fluorometer equipped with an Ushio UXL-75Xe xenon arc lamp and a PTI 814 photomultiplier detection system. A $1 \mathrm{~cm} \times 1 \mathrm{~cm}$ quartz cell was used to acquire the fluorescence spectra with the right-angle geometry for a Py-EP concentration of $0.01 \mathrm{~g} \cdot \mathrm{L}^{-1}$. A triangular quartz cell was used for front-face geometry measurements to minimize the inner filter effect when 
acquiring the fluorescence spectra at Py-EP concentrations of 10 g.L $\mathrm{L}^{-1}$. Fluorescence spectra of solutions of Py-EPs and wax in toluene were acquired by exciting the solution at $344 \mathrm{~nm}$ and acquiring the emission spectra from 350 to $600 \mathrm{~nm}$. The fluorescence measurements were acquired with a cryostat from Oxford Instruments (Optistat DN) fitted inside the steady-state fluorometer. Before each measurement, the solutions were placed in the cryostat where they were degassed for 30-40 minutes under a gentle flow of $\mathrm{N}_{2}$ to remove undesired oxygen that quenches pyrene fluorescence. Measurements were carried out at temperatures ranging from $-30( \pm 0.2)$ to $+25( \pm$ $0.2)^{\circ} \mathrm{C}$ and before each set of experiments, the solutions were heated to room temperature to erase all pre-association history before bringing the solution to the desired temperature. The solutions were left in the cryostat for $10 \mathrm{~min}$ after the cryostat had reached the set temperature before any fluorescence spectrum was acquired.

UV-Visible Spectrophotometer. Absorption spectra were acquired between 200 and $600 \mathrm{~nm}$ on a Cary 100 UV-Vis spectrophotometer. Quartz cells having a 0.1-10 mm path length were employed for these measurements.

Labeling of the EP Copolymers. The polymers were first maleated to yield EP-MA ${ }^{28}$ and then fluorescently labeled with 1-pyrenemethylamine ${ }^{29}$ according to a procedure described earlier ${ }^{19,22}$ and shown in Scheme 1. 
A)

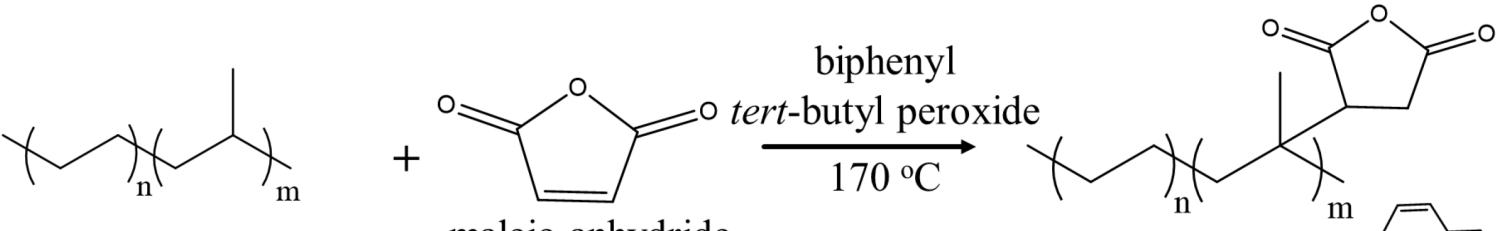
maleic anhydride

B)

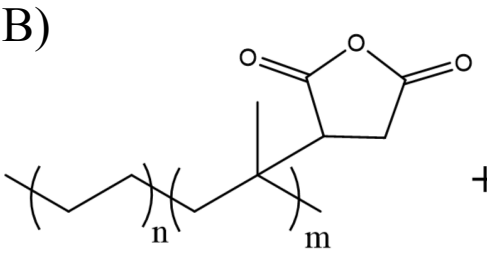<smiles>CCc1ccc2ccc3cccc4ccc1c2c34</smiles>

$\frac{\text { dodecane }}{180^{\circ} \mathrm{C}}$

1-pyrenemethylamine

Scheme 1. Reaction scheme for A) the maleation of the EP copolymer and B) the pyrenelabeling of the maleated EP copolymers.

\section{RESULTS AND DISCUSSION}

An earlier study has established that the molar fraction of pyrene labels forming excimer intermoleculally, namely $f_{\text {inter, }}$ accurately describes the level of interactions between Py-EP copolymers in toluene. ${ }^{19}$ In particular, a plot of $f_{\text {inter }}$ as a function of temperature provides valuable information on the effect of temperature on the interactions between EP copolymers in toluene. Such $f_{\text {inter-vs- }} T$ plots were constructed in the present study to assess the effect that the presence of wax has on the interactions between EP copolymers having different crystallinities. The crystallinity of the different EP copolymers was characterized as well as their maleation and pyrene labeling as follows.

Chemical Composition of the Py-EP Samples. The ethylene content of the EP samples was determined by using a procedure developed by Randall based on ${ }^{13} \mathrm{C}$ NMR. ${ }^{25}$ To this end, ${ }^{13} \mathrm{C}$ NMR spectra of all EP copolymers were acquired and two representative examples are shown in Figure S1 as Supporting Information (SI). Using Randall's procedure, ${ }^{25}$ the ethylene content was 
determined and provided in Table 2. In this report, the polyolefin samples are described based on their ethylene content in mol\% where $\operatorname{EP}(78-1)$ indicates an EP copolymer with a $78 \mathrm{~mol} \%$ ethylene content. The "-1" label indicates that this sample was the first semicrystaline EP copolymer with an ethylene content of $78 \mathrm{~mol} \%$ to be studied.

The EP copolymers were then maleated to yield EP-MA and fluorescently labeled with 1-pyrenemethylamine according to Scheme 1. To this end, FTIR spectroscopy was applied to assess the success of the different reactions. The FTIR spectrum of EP(78) in Figure S2 shows two absorption bands at $1462 \mathrm{~cm}^{-1}$ and $1379 \mathrm{~cm}^{-1}$ which are due to the methylene and methyl units along the EP backbone, respectively. Since the FTIR spectrum of an EP-MA sample with fully cyclized succinic anhydride rings has a strong absorption band at $1785 \mathrm{~cm}^{-1}$ due to the succinic anhydride carbonyls and no absorption at $1705 \mathrm{~cm}^{-1}$ where the succinic acid carbonyls absorb, FTIR was applied to ensure complete dehydration of EP-MA by monitoring the absence of absorption at $1705 \mathrm{~cm}^{-1}$. After pyrene-labeling, a new absorption band appeared at $1710 \mathrm{~cm}^{-1}$ characteristic of the succinimide carbonyls while the band at $1785 \mathrm{~cm}^{-1}$ disappeared (Trace $\mathrm{C}$ in Figure S2) following the reaction of succinic anhydride with 1-pyrenemethylamine.

FTIR spectra were normalized at $1462 \mathrm{~cm}^{-1}$ and the absorbance ratios $A b s(1379$ $\left.\mathrm{cm}^{-1}\right) / A b s\left(1462 \mathrm{~cm}^{-1}\right), \operatorname{Abs}\left(1785 \mathrm{~cm}^{-1}\right) / A b s\left(1462 \mathrm{~cm}^{-1}\right)$, and $\operatorname{Abs}\left(1710 \mathrm{~cm}^{-1}\right) / A b s\left(1462 \mathrm{~cm}^{-1}\right)$ were determined. They are listed in Table 2 . The $A b s\left(1379 \mathrm{~cm}^{-1}\right) / A b s\left(1462 \mathrm{~cm}^{-1}\right)$ ratio provided a measure of the ethylene content of the EP copolymers which agreed with the ${ }^{13} \mathrm{C}$ NMR results, with a larger $A b s\left(1379 \mathrm{~cm}^{-1}\right) / A b s\left(1462 \mathrm{~cm}^{-1}\right)$ ratio indicating a smaller ethylene content. EP copolymers having a similar ethylene content as determined by ${ }^{13} \mathrm{C}$ NMR also yielded similar $\operatorname{Abs}\left(1379 \mathrm{~cm}^{-1}\right) / A b s\left(1462 \mathrm{~cm}^{-1}\right)$ ratios. Finally, the $A b s\left(1379 \mathrm{~cm}^{-1}\right) / A b s\left(1462 \mathrm{~cm}^{-1}\right)$ ratio of the EP copolymers did not change after conducting the maleation and pyrene-labeling reaction 
confirming that the chemical composition of the copolymers in terms of ethylene and propylene contents was not affected by these reactions. However it must be pointed out that the procedure for pyrene-labeling has been shown earlier to induce some chain scission for $\mathrm{EP}(60-1)$ and $\mathrm{EP}(78-$ 1) resulting in a shift in the molecular weight distribution to lower molar masses. ${ }^{19}$ The numberaverage molecular weight $\left(M_{\mathrm{n}}\right)$ of $\mathrm{EP}(60-1)$ decreased from $59 \mathrm{~K}(\mathrm{PDI}=2.1)$ to $25 \mathrm{~K}(\mathrm{PDI}=2.4)$ for Py(108)-EP(60-1). Similarly, $M_{\mathrm{n}}$ decreased from $55 \mathrm{~K}$ (PDI = 2.6) for $\mathrm{EP}(78-1)$ to $33 \mathrm{~K}$ (PDI $=2.8)$ for Py(116)-EP(78-1). Although no molecular weight analysis was carried out for the EP(612) and EP(78-2) samples, their similar chemical composition established by FTIR and ${ }^{13} \mathrm{C}$ NMR analysis in Table 2 and the identical intrinsic viscosity profiles reported in Figure 1 for the two pyrene-labeled semicrystalline and amorphous EP copolymers suggest that $\mathrm{Py}(103)-\mathrm{EP}(61-2)$ and Py(123)-EP(78-2) have MWDs that are similar to those of Py(108)-EP(60-1) and Py(116)-EP(781), respectively. Furthermore the behavior in solution of the lower molecular weight Py-EP samples was found to remain identical to that of the unmodified EP copolymers based on intrinsic viscosity measurements carried out as a function of temperature in toluene. Consequently the behaviour of the Py-EP samples probed by fluorescence is expected to closely reflect that of the unmodified samples.

The pyrene content $\left(\lambda_{\mathrm{Py}}\right)$ of the Py-EP samples expressed in $\mu$ mol of pyrene per gram of polymer was determined by UV-Vis absorption by comparison of the pyrene absorbance at 344 $\mathrm{nm}$ in toluene with that of 1-pyrenemethyl-succinimide used as a model compound as was done in an earlier publication. ${ }^{19}$ The $\lambda_{\text {Py }}$ values are listed in Table 2 and they were used to describe the PyEP samples. For example, the sample Py(116)-EP(78-1) had a pyrene content of $116 \mu \mathrm{mol} / \mathrm{g}$ and was the first sample with an ethylene content of $78 \mathrm{~mol} \%$ to be studied. 
Table 2. Chemical composition of Py-EP sample.

\begin{tabular}{|c|c|c|c|c|c|}
\hline Polymer Type & $\begin{array}{c}\lambda_{\text {Py }} \\
\left(\mu \mathrm{mol}^{-1} \mathrm{~g}^{-1}\right) \\
(\mathrm{UV}-\mathrm{Vis} \\
\text { absorption) }\end{array}$ & $\frac{A b s\left(1379 \mathrm{~cm}^{-1}\right)}{A b s\left(1462 \mathrm{~cm}^{-1}\right)}$ & $\frac{A b s\left(1785 \mathrm{~cm}^{-1}\right)}{A b s\left(1462 \mathrm{~cm}^{-1}\right)}$ & $\frac{A b s\left(1710 \mathrm{~cm}^{-1}\right)}{A b s\left(1462 \mathrm{~cm}^{-1}\right)}$ & $\begin{array}{c}\text { Ethylene } \\
\text { Content Mole\% } \\
\left({ }^{13} \mathrm{C} \mathrm{NMR}\right)\end{array}$ \\
\hline EP(60-1) & - & 0.80 & - & - & 60 \\
\hline ЕР(60-1)-МА & - & 0.79 & 0.22 & - & - \\
\hline Рy(108)-EP(60-1) & 108 & 0.80 & - & 0.20 & - \\
\hline EP(61-2) & - & 0.79 & - & - & 61 \\
\hline ЕР(61-2)-МА & - & 0.78 & 0.23 & - & - \\
\hline Py(103)-EP(61-2) & 103 & 0.78 & - & 0.17 & - \\
\hline EP(78-1) & - & 0.55 & - & - & 78 \\
\hline ЕР(78-1)-МА & - & 0.55 & 0.23 & - & - \\
\hline Py(116)-EP(78-1) & 116 & 0.56 & - & 0.28 & - \\
\hline $\operatorname{EP}(78-2)$ & - & 0.66 & - & - & 78 \\
\hline ЕР(78-2)-МА & - & 0.60 & 0.21 & - & - \\
\hline Py(123)-EP(78-2) & 123 & 0.61 & - & 0.22 & - \\
\hline
\end{tabular}

Microstructure of EP Copolymers. Differential scanning calorimetry (DSC) experiments were conducted on the EP copolymer samples in the solid state. As shown in Figure S3, a thermal transition due to melting was observed for the semicrystalline samples while no thermal transition was observed for the amorphous samples. The $T_{\mathrm{m}}$ and enthalpy of melting $\left(\Delta_{\mathrm{m}} H\right)$ values retrieved from the DSC experiments conducted with the EP copolymers are listed in Table 3 . The $\Delta_{\mathrm{m}} H$ and $T_{m}$ results for $\operatorname{EP}(78-1)$ and $\operatorname{EP}(78-2)$ clearly indicate that these samples are similar in terms of crystallinity and melting profile. In turn this conclusion agrees with their similar chemical composition found by FTIR and ${ }^{13} \mathrm{C}$ NMR spectroscopy (see Table 2). 
Table 3. Melting temperature $\left(T_{m}\right)$ and enthalpy $\left(\Delta_{\mathrm{m}} H\right)$ of EP copolymers obtained from DSC measurements.

\begin{tabular}{|c|c|c|}
\hline Polymer Name & $T_{m}\left({ }^{\circ} \mathrm{C}\right)$ & $\Delta_{\mathrm{m}} H\left(\mathrm{~J}^{\mathrm{g}}{ }^{-1}\right)$ \\
\hline EP(78-1) & 31 & 31 \\
\hline EP(78-2) & 32 & 25 \\
\hline
\end{tabular}

Solution Behaviour of EP Copolymers. Viscosity measurements were carried out between $-10{ }^{\circ} \mathrm{C}$ and $+20{ }^{\circ} \mathrm{C}$ for all EP copolymers in toluene to determine how their intrinsic viscosity $[\eta]$ varied as a function of temperature. The resulting trends are shown in Figure 1. For all the semicrystalline samples (Figure 1C-D), $[\eta]$ increased sharply with increasing temperature up to $0{ }^{\circ} \mathrm{C}$ and remained relatively constant afterward. As has been inferred for semicrystalline EP copolymers earlier, ${ }^{3,4}$ the break point in the $[\eta]$ profile is most likely due to a change in the hydrodynamic volume of the polymer coil $\left(V_{\mathrm{h}}\right)$ resulting from the melting of crystalline microdomains between long ethylene stretches inside the polymer coil at temperatures higher than $0{ }^{\circ} \mathrm{C} .{ }^{4}$ In this report, the temperature below which crystalline microdomains are generated in solution will be referred to as $T_{\mathrm{C}}$. For the amorphous Py(108)-EP(60-1) and Py(103)-EP(61-2) samples, $[\eta]$ remained relatively constant with increasing temperature in Figure $1 \mathrm{~A}$ and $\mathrm{B}$ as expected based on the inability of the amorphous samples to form crystalline microdomains in solution and thus undergo drastic changes in hydrodynamic volume. 


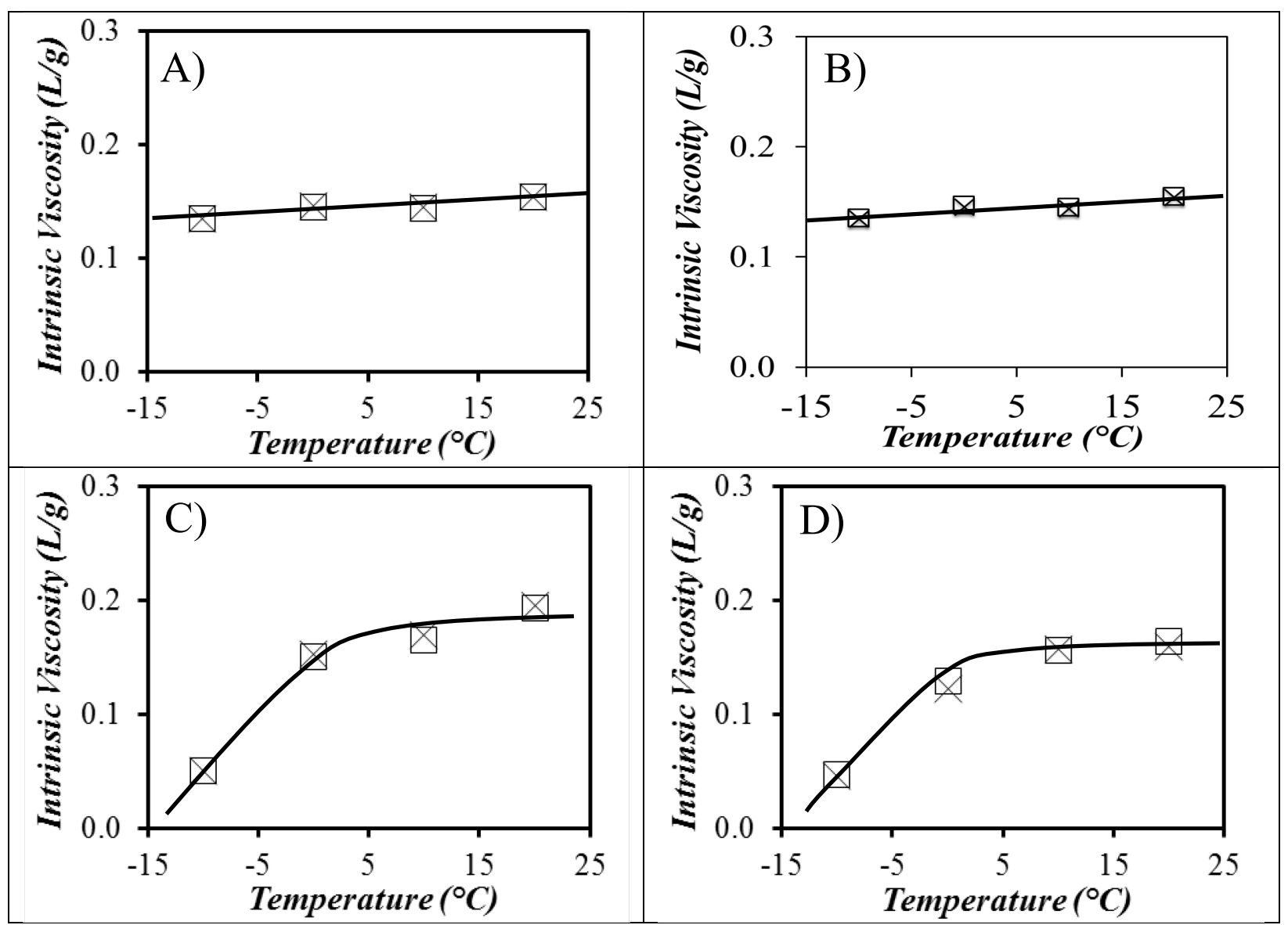

Figure 1. Intrinsic viscosity obtained by using $(\times)$ relative and $(\square)$ specific viscosity measurements in toluene at various temperatures for A) Py(108)-EP(60-1), B) Py(103)-EP(61-2), C) Py(116)EP(78-1), and D) Py(123)-EP(78-2).

Pyrene Excimer Formation in the Presence of Wax. Previous experiments based on FRET and PEF demonstrated that the existence of intermolecular associations between EP copolymers could be demonstrated qualitatively and quantitatively by the former and latter techniques, respectively. ${ }^{19}$ In particular, PEF experiments were shown to yield the molar fraction of pyrene labels forming pyrene excimer intermolecularly $\left(f_{\text {inter }}\right)$ in solution. ${ }^{19}$ This procedure is now employed to determine the effect that the presence of wax has on the level of EP interactions in the solution as a function of temperature. The process of excimer formation between pyrene labels 
covalently attached onto a macromolecule, or PyLM for pyrene-labeled macromolecule, is described in Scheme 2.

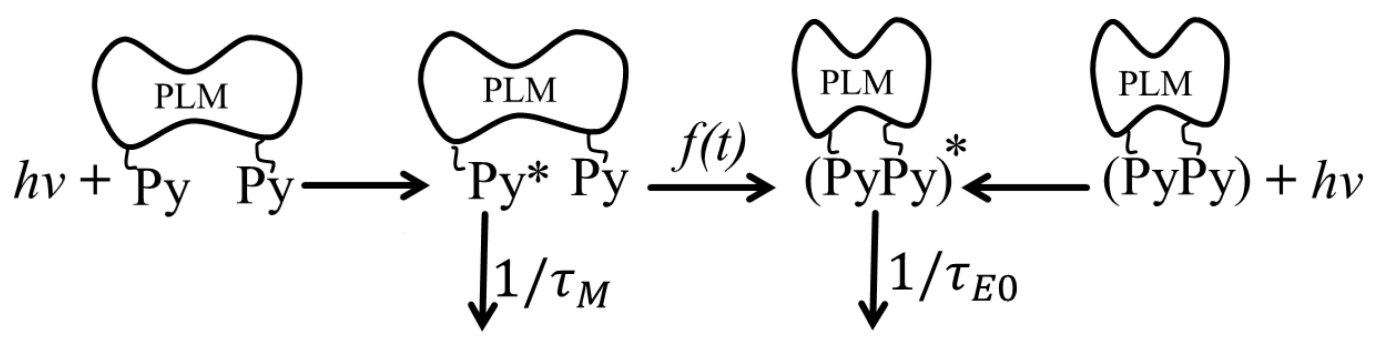

Scheme 2. Kinetics of pyrene excimer formation for a PyLM.

In Scheme 2, irradiation of a PyLM with UV light leads to the excitation of some pyrene monomers and pyrene aggregates. Excitation of a pyrene aggregate results in instantaneous excimer formation with excimers that emit with a natural lifetime $\tau_{\mathrm{E} 0}$. Excitation of a pyrene monomer can lead to monomer fluorescence that occurs with a lifetime $\tau_{\mathrm{M}}$ or excimer formation if diffusive encounters take place between the excited pyrene and a nearby ground-state pyrene. The excited pyrene monomer emission is characterized by four sharp fluorescence bands between 360 $\mathrm{nm}$ and $425 \mathrm{~nm}$, whereas the pyrene excimer features a broad and structureless emission centered at $480 \mathrm{~nm}$. These spectral features are presented in Figure 2 that shows the typical fluorescence spectrum of a Py-EP sample in toluene in the absence and presence of wax. The fluorescence intensity of the pyrene excimer $I_{\mathrm{E}}$ and monomer $I_{\mathrm{M}}$ can be calculated by integrating the fluorescence spectrum over a well-defined range of wavelengths. Traditionally, this laboratory has used a wavelength range between 372 and $379 \mathrm{~nm}$ corresponding to the first peak (I) in the fluorescence spectrum to calculate $I_{\mathrm{M}}$ for Py-EP samples in toluene. The choice of the fluorescence peak furthest to the left to calculate $I_{\mathrm{M}}$ was made to minimize a possible overlap between the monomer and excimer emissions. In the present case however, this procedure appeared to be flawed as the presence of wax led to an apparent decrease in the intensity of the fluorescence peak 
at $376 \mathrm{~nm}$. The origin of this effect was attributed to light scattering generated by wax aggregates that resulted in a substantial lengthening of the light path in the solution associated with reabsorption of the first fluorescence peak.

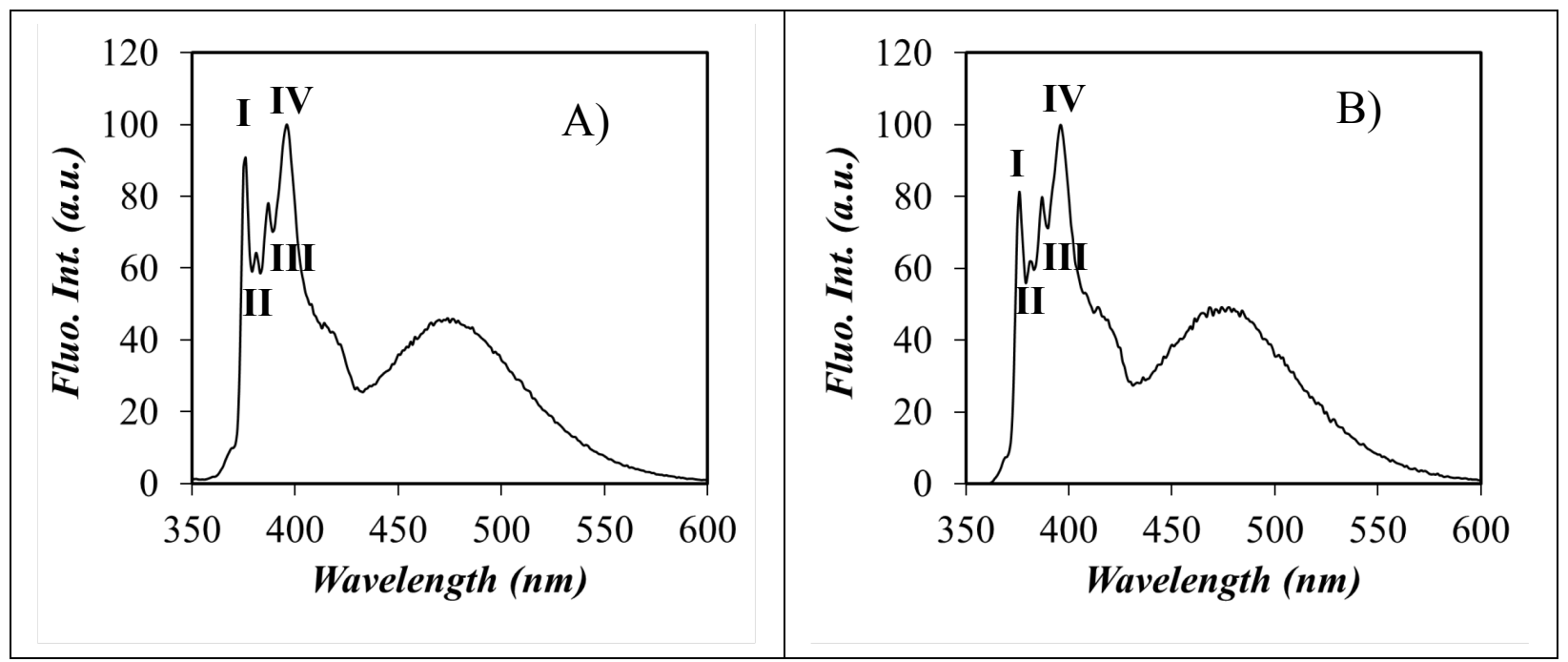

Figure 2. Steady-state fluorescence spectra of the Py(123)-EP(78-2) sample A) without and B) with wax in toluene. ([Poly $\left.]=10 \mathrm{~g} \cdot \mathrm{L}^{-1}, \lambda_{\mathrm{ex}}=344 \mathrm{~nm}\right)$

As shown in Figure 2A and B, the peak at $376 \mathrm{~nm}$ was supressed after adding wax to the 10 g.L. ${ }^{-1} \mathrm{Py}(123)-\mathrm{EP}(78-2)$ solution. Since the determination of $f_{\text {inter }}$ is based on the comparison of the $I_{\mathrm{E}} / I_{\mathrm{M}}$ ratios, a depression in $I_{\mathrm{M}}$ obtained for the Py-EP solutions with wax would affect the $I_{\mathrm{E}} / I_{\mathrm{M}}$ ratio resulting an erroneous $f_{\text {inter }}$ value. Fortunately, inspection of the fluorescence spectra indicated that the fourth peak (IV) was much less affected by the presence of wax. Therefore, the wavelengths between 394 and $399 \mathrm{~nm}$ corresponding to the fourth peak (IV) in the spectrum were selected instead to calculate $I_{\mathrm{M}}$ to minimize the interference induced by light scattering on the fluorescence spectrum at the lower wavelengths. The wavelengths range between 500 and $530 \mathrm{~nm}$ was chosen for $I_{\mathrm{E}}$ to minimize any overlap that might exist between the fluorescence of the 
monomer and excimer. The choice of a different wavelength range to integrate the monomer signal will be shown later on to have a minimal impact on the calculation of $f_{\text {inter. }}$.

This procedure was implemented to determine the $I_{\mathrm{E}} / I_{\mathrm{M}}$ ratio for the $10 \mathrm{~g} / \mathrm{L} \mathrm{Py}-\mathrm{EP}$ solution. Equation 1 could then be applied to relate the $I_{\mathrm{E}} / I_{\mathrm{M}}$ ratio to the local pyrene concentration $[P y]_{l o c}$ experienced by an excited pyrene monomer attached onto the Py-EP samples. ${ }^{30}$ In Equation 1 , $K(T)$ is a multiplication factor which is a function of the quantum yields of the pyrene monomer and excimer and the rate constants for excimer formation and dissociation. As a result, $K(T)$ is expected to vary with temperature as already discussed in an earlier report. ${ }^{19}$ At a same temperature however, an increase in $I_{\mathrm{E}} / I_{\mathrm{M}}$ reflects an increase in $[P y]_{\mathrm{loc}}$ which results from increased intermolecular interactions. In turn, a rise in intermolecular interactions can be due to an increase in the concentration of the PyLMs, a change in the solvent quality toward the macromolecule, or the presence of an external species that would enhance intermolecular associations such as wax could do to the Py-EP chains in solution. When a PyLM undergoes both intra- and intermolecular interactions, its fluorescence spectrum yields the ratio $I_{\mathrm{E}} / I_{\mathrm{M}}\left(\begin{array}{l}\text { intra \& } \\ \text { inter }\end{array}\right)$ whereas if the PyLM undergoes solely intramolecular interactions, the fluorescence spectrum yields the ratio $I_{\mathrm{E}} / I_{\mathrm{M}}($ intra $)$. In turn, the ratios $I_{\mathrm{E}} / I_{\mathrm{M}}\left(\begin{array}{l}\text { intra \& } \\ \text { inter }\end{array}\right)$ and $I_{\mathrm{E}} / I_{\mathrm{M}}($ intra $)$ are equal to $K(T) \times[P y]_{\mathrm{loc}}\left(\begin{array}{l}\text { intra \& } \\ \text { inter }\end{array}\right)$ and $K(T) \times[P y]_{\text {loc }}$ (intra), respectively. The molar fraction of PyLMs forming excimer intermolecularly $\left(f_{\text {inter }}\right)$ can then be determined from Equation 2. Consequently, Equation 2 was applied to determine the temperature profile of $f_{\text {inter }}$ for the Py-EP copolymers listed in Table 2 where the EP backbone exhibits different levels of crystallinity, in the absence and presence of wax.

$$
I_{\mathrm{E}} / I_{\mathrm{M}}=K(T) \times[P y]_{\mathrm{loc}}
$$




$$
f_{\text {inter }}=\frac{[P y]_{\text {loc }}\left(\begin{array}{l}
\text { inter } \text { intra } \\
\text { int }
\end{array}\right)-[P y]_{l o c}(\text { intra })}{[P y]_{l o c}\left(\begin{array}{l}
\text { inter } \text { intra } \\
\text { intra }
\end{array}\right)}=\frac{I_{E} / I_{M}\left(\begin{array}{l}
\text { inter \& } \\
\text { intra }
\end{array}\right)-I_{E} / I_{M}(\text { intra })}{I_{E} / I_{M}\left(\begin{array}{l}
\text { inter } \text { intra } \\
\text { intra }
\end{array}\right)}
$$

To this end, the ratio $I_{\mathrm{E}} / I_{\mathrm{M}}\left(\begin{array}{l}\text { intra \& } \\ \text { inter }\end{array}\right)$ was obtained by acquiring the fluorescence spectra of the $10 \mathrm{~g} / \mathrm{L}$ Py-EP solutions in the presence of wax (see Figure 2). To calculate $I_{\mathrm{E}} / I_{\mathrm{M}}($ intra) in Equation 2, the fluorescence spectrum of a dilute $\left(0.01\right.$ g. $\left.\mathrm{L}^{-1}\right)$ solution of Py-EP needed to be acquired in the presence of 10 g. $\mathrm{L}^{-1}$ of the unlabeled macromolecule to ensure that only intramolecular excimer formation would be observed. Calculating $I_{\mathrm{E}} / I_{\mathrm{M}}($ intra $)$ in the presence of wax was challenging however due to the strong emission of the 10 g. $\mathrm{L}^{-1}$ wax solution that interfered with the emission of a 0.01 g.L $\mathrm{L}^{-1}$ Py-EP solution as shown in Figure 3A. The fluorescence of wax did not affect the fluorescence spectra of the 10 g.L $\mathrm{L}^{-1} \mathrm{Py}-\mathrm{EP}$ solution in Figure 2B where the much higher pyrene concentration led to a much stronger pyrene emission that dwarfed that of wax. 


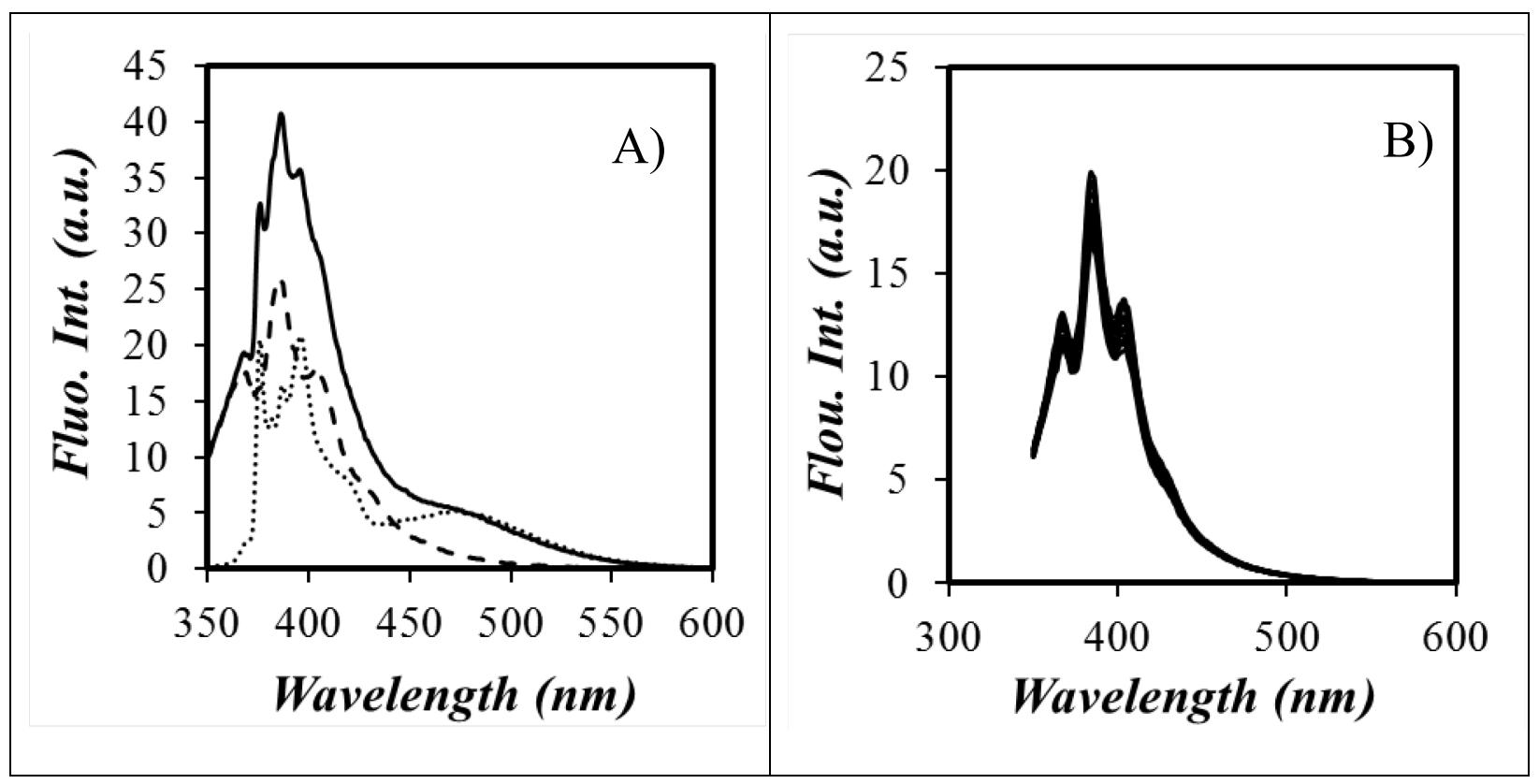

Figure 3. A) Fluorescence spectra of (-) the mixture of 0.01 g.L $\mathrm{L}^{-1} \mathrm{Py}(108)-\mathrm{EP}(60-1), 10$ g.L $\mathrm{L}^{-1}$

EP(60-1), and 10 g.L ${ }^{-1}$ wax, $(\cdots)$ the mixture of 0.01 g.L ${ }^{-1}$ Py(108)-EP(60-1) and 10 g.L $L^{-1}$ EP(601), and (- - -) the 10 g. $\mathrm{L}^{-1}$ wax solution. B) Fluorescence spectra of wax as a function of temperature. From top to bottom, temperature increases from $-30^{\circ} \mathrm{C}$ to $+25^{\circ} \mathrm{C}$. (Solvent: toluene, $\left.\lambda_{\mathrm{ex}}=344 \mathrm{~nm}\right)$

Therefore, subtracting the fluorescence spectrum of the $10 \mathrm{~g} . \mathrm{L}^{-1}$ wax solution in toluene from the fluorescence spectrum of the mixture containing 10 g.L $\mathrm{L}^{-1}$ wax, 10 g.L. ${ }^{-1} \mathrm{EP}$, and 0.01 g.L $L^{-1}$ Py-EP was necessary to obtain the actual spectrum of Py-EP which was used to calculate $I_{\mathrm{E}} / I_{\mathrm{M}}($ intra $)$. Since this operation needed to be accomplished at all temperatures, the fluorescence spectra of the 10 g. $\mathrm{L}^{-1}$ wax solution were acquired as a function of temperature as shown in Figure 3B. The wax fluorescence spectra appeared to be little affected by changes in temperature between -30 and $+25^{\circ} \mathrm{C}$. To account for differences in fluorometer configuration between the different days that the fluorescence experiments were carried out, the fluorescence spectra of the 10 g.L $\mathrm{L}^{-1}$ wax solution and the 10 g.L. ${ }^{-1}$ wax, 10 g.L $\mathrm{L}^{-1} \mathrm{EP}$, and 0.01 g.L $\mathrm{L}^{-1}$ Py-EP mixture were normalized at 
$360 \mathrm{~nm}$ where pyrene does not emit and the wax spectrum shown as a dashed line in Figure 3A was subtracted from the latter spectrum to yield the fluorescence spectrum of the 10 g.L. $\mathrm{L}^{-1}$ wax, 10 g.L $\mathrm{L}^{-1}$ EP, and 0.01 g.L $\mathrm{L}^{-1}$ Py-EP mixture as shown by the dotted line in Figure 3A. This procedure yielded the expected fluorescence spectrum for Py-EP in toluene which demonstrated its validity for the purpose of this study.

Since engine oils contain a few wt $\%$ of VII and wax, the fluorescence spectra of the Py-EP toluene solutions with or without $10 \mathrm{~g} . \mathrm{L}^{-1}$ wax were acquired as a function of temperature as shown in Figure 4 for the $\operatorname{Py}(103)-\mathrm{EP}(61-2)$ sample. Their $I_{\mathrm{E}} / I_{\mathrm{M}}\left(\begin{array}{l}\text { intra \& } \\ \text { inter }\end{array}\right)$ and $I_{\mathrm{E}} / I_{\mathrm{M}}($ intra $)$ ratios were calculated and those obtained for the amorphous Py(103)-EP(61-2) and semicrystalline Py(123)EP(78-2) samples were plotted in Figure 5 as a function of temperature. The others are shown in Figure $\mathrm{S} 4$ in SI. The $I_{\mathrm{E}} / I_{\mathrm{M}}$ ratios of the amorphous $\mathrm{Py}(103)-\mathrm{EP}(61-2)$ solution without and with wax were found to increase continuously with increasing temperature in Figure 5A and B, respectively. This is the expected behavior for amorphous samples because the dissociation rate constant $\left(k_{-1}\right)$ of the pyrene excimer is negligible in this temperature regime, ${ }^{30}$ and $[P y]_{\text {loc }}$ does not change much with temperature for these amorphous samples (see Figure 1A and B). Under these conditions, the increase in $I_{\mathrm{E}} / I_{\mathrm{M}}$ with increasing temperature only reflects the increase in the rate constant $\left(k_{\text {diff }}\right)$ for diffusion-controlled pyrene excimer formation associated with the decrease in solvent viscosity due to the increase in temperature. Similar trends were found for the Py(108)EP(60-1) solutions in Figure S4. 

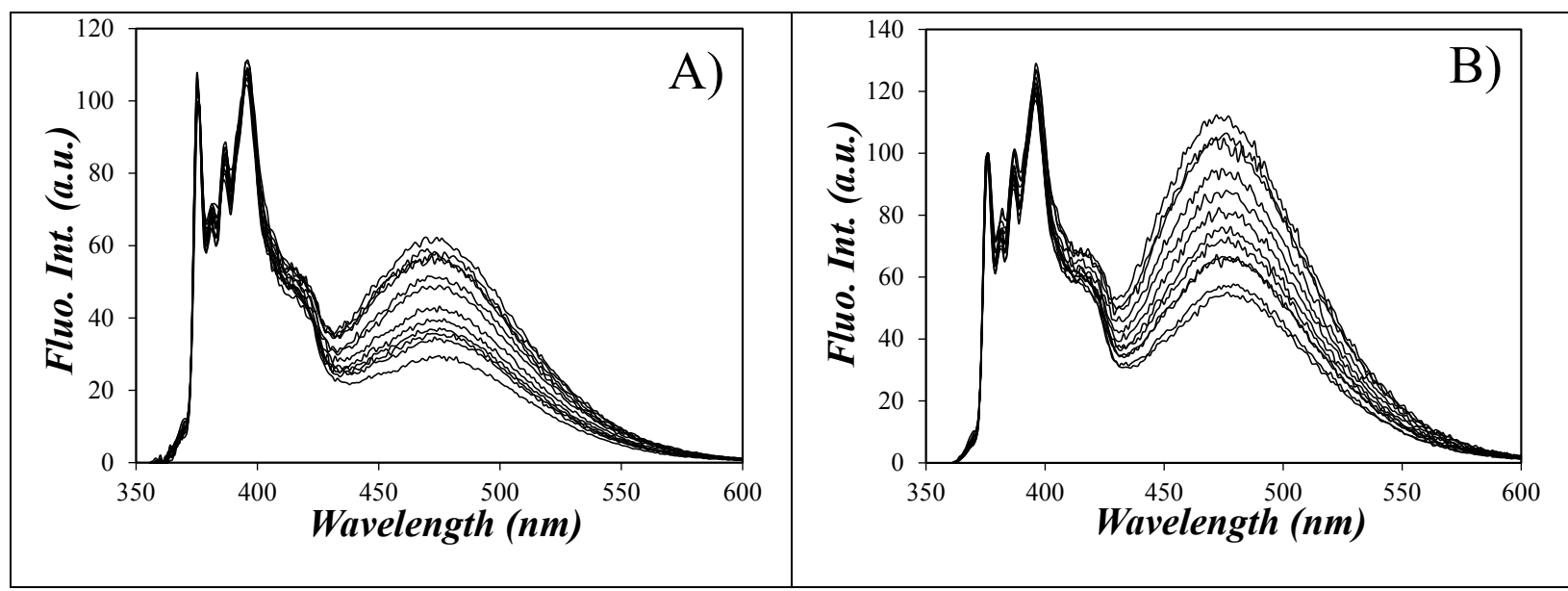

Figure 4. Fluorescence spectra of $\mathrm{Py}(103)-\mathrm{EP}(61-2)$ acquired as a function of temperature for $\mathrm{A})$ the 10 g.L $\mathrm{L}^{-1}$ wax, 10 g.L. ${ }^{-1}$ EP, and 0.01 g.L $\mathrm{L}^{-1}$ Py-EP and B) the 10 g.L $\mathrm{L}^{-1}$ wax and 10 g.L ${ }^{-1}$ Py-EP mixtures. $T$ ranges between -30 and $+25^{\circ} \mathrm{C}$.

For the Py(123)-EP(78-2) solutions without or with wax shown in Figure $5 \mathrm{C}$ and $\mathrm{D}$, the plots of $I_{\mathrm{E}} / I_{\mathrm{M}}\left(\begin{array}{l}\text { intra \& } \\ \text { inter }\end{array}\right)$ as a function of temperature resulted in a very different behavior from that of the amorphous samples. An increase in solution temperature induced first an increase in $I_{\mathrm{E}} / I_{\mathrm{M}}\left(\begin{array}{l}\text { intra \& } \\ \text { inter }\end{array}\right)$, followed by a decrease in $I_{\mathrm{E}} / I_{\mathrm{M}}\left(\begin{array}{l}\text { intra \& } \\ \text { inter }\end{array}\right)$ at intermediate temperatures, before the increase in $I_{\mathrm{E}} / I_{\mathrm{M}}\left(\begin{array}{l}\text { intra \& } \\ \text { inter }\end{array}\right)$ resumed upon increasing the solution temperature further. The drop in $I_{\mathrm{E}} / I_{\mathrm{M}}\left(\begin{array}{l}\text { intra \& } \\ \text { inter }\end{array}\right)$ observed for the Py-EP semicrystalline samples at intermediate temperatures has been attributed to a decrease in excimer formation due to a decrease in $[P y]_{\text {loc }}$ resulting from the melting of microcrystals generated by long polyethylene sequences in the copolymer. ${ }^{2,19}$ After melting of the microcrystals is complete, $[P y]_{\text {loc }}$ does not change much and the $I_{\mathrm{E}} / I_{\mathrm{M}}\left(\begin{array}{l}\text { intra \& } \\ \text { inter }\end{array}\right)$ 
ratio increases continuously with increasing temperature in the same manner as for the amorphous EP copolymers due to the increase in $k_{\text {diff. }}$.

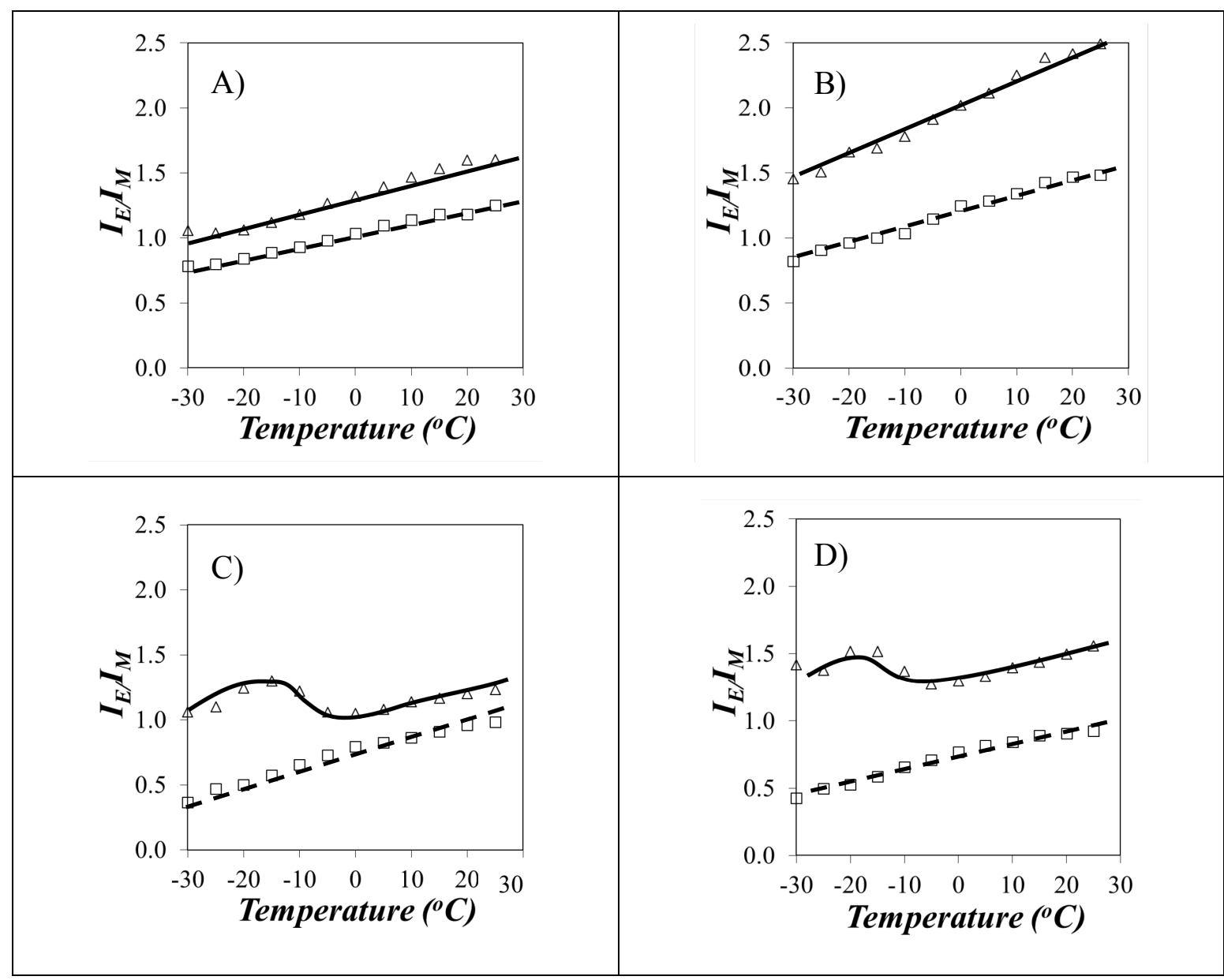

Figure 4. Plots of $I_{E} / I_{M}$-vs- $T$ for the mixtures of $(\triangle)$ Py-EP $\left(10\right.$ g.L $\left.\mathrm{L}^{-1}\right)$ and $(\square)$ Py-EP $\left(0.01\right.$ g.L $\left.\mathrm{L}^{-1}\right)$ and EP (10 g.L - $\left.^{-1}\right)$. A) Py(103)-EP(61-2) without wax, B) Py(103)-EP(61-2) with 10 g.L . $^{-1}$ wax, C) Py(123)-EP(78-2) without wax, and D) Py(123)-EP(78-2) with 10 g.L.- wax.

Beside the experiments conducted on the mixture containing 10 g.L $\mathrm{L}^{-1}$ Py-EP and 10 g. $\mathrm{L}^{-1}$ wax, the fluorescence spectra of toluene solutions containing a 10 g. $\mathrm{L}^{-1}$ excess of unlabeled EP copolymer, 0.01 g.L $\mathrm{L}^{-1}$ Py-EP, and 10 g.. $\mathrm{L}^{-1}$ wax were also acquired as a function of temperature 
for all the EP copolymers to obtain the ratio $I_{\mathrm{E}} / I_{\mathrm{M}}($ intra $)$. The $I_{\mathrm{E}} / I_{\mathrm{M}}$ (intra) of all the fluorescence spectra were calculated and they were plotted in Figures 4 and S4 as a function of temperature. For all four Py-EP solutions, the ratio $I_{\mathrm{E}} / I_{\mathrm{M}}$ (intra) increased continuously with increasing temperature in Figure 5. This behavior was expected, since the Py-EP macromolecules were well separated thanks to the excess of unlabeled EP copolymer present in the solution ensuring that $[P y]_{\text {loc }}$ remained constant with temperature and that the $I_{\mathrm{E}} / I_{\mathrm{M}}$ ratio responded solely to the decrease in viscosity taking place with increasing temperature. As was already pointed out, a decrease in viscosity leads to an increase in diffusive encounters, which is reflected by an increase in excimer formation, and thus in the $I_{\mathrm{E}} / I_{\mathrm{M}}$ ratio. It is important to point out at this stage that PEF is a phenomenon that involves a few tens of monomers in a PyLM so that polymer entanglements are not relevant at the relatively low polymer concentrations studied. ${ }^{31-33}$

Equation 2 was applied to the trends shown in Figures 5 and S4 to yield the $f_{\text {inter }}$ values of the Py-EP solutions without or with wax which were plotted as a function of temperature in Figure 6. For all solutions of amorphous Py-EP in toluene, $f_{\text {inter }}$ increased after adding wax to the solution. This behavior indicates that the presence of wax in toluene induces aggregation of amorphous PyEP copolymers. The aggregation then resulted in an increase in the probability of having pyrenepyrene encounters in the solution and thus a higher $f_{\text {inter }}$ value. In the case of the two amorphous Py(108)-EP(60-1) and Py(103)-EP(61-2) samples, $f_{\text {inter }}$ increased from $0.28 \pm 0.02$ to $0.43 \pm 0.01$ and from $0.22 \pm 0.02$ to $0.40 \pm 0.01$ upon addition of wax, respectively.

For the solutions of all semicrystalline Py-EPs, the transition induced by the formation of crystalline microdomains was still observed in the presence of wax. Moreover, $f_{\text {inter }}$ increased after addition of wax at temperatures larger than the crystallization temperature $\left(T_{\mathrm{C}}\right)$ where the polymers were soluble. At temperatures lower than $T_{\mathrm{C}}$ however, the formation of microcrystals in the Py-EP 
semicrystalline samples maximized polymer-polymer contacts and the wax molecules were expelled from the microcrystals. Since $f_{\text {inter }}$ reflected $[P y]_{\text {loc }}$ after the wax had been expelled from the microcrystals, it was little affected by the presence of wax at temperatures lower than $T_{\mathrm{C}}$. The $f_{\text {inter }}$ values obtained in the different temperature regimes for all EP samples have been listed in Table 4.

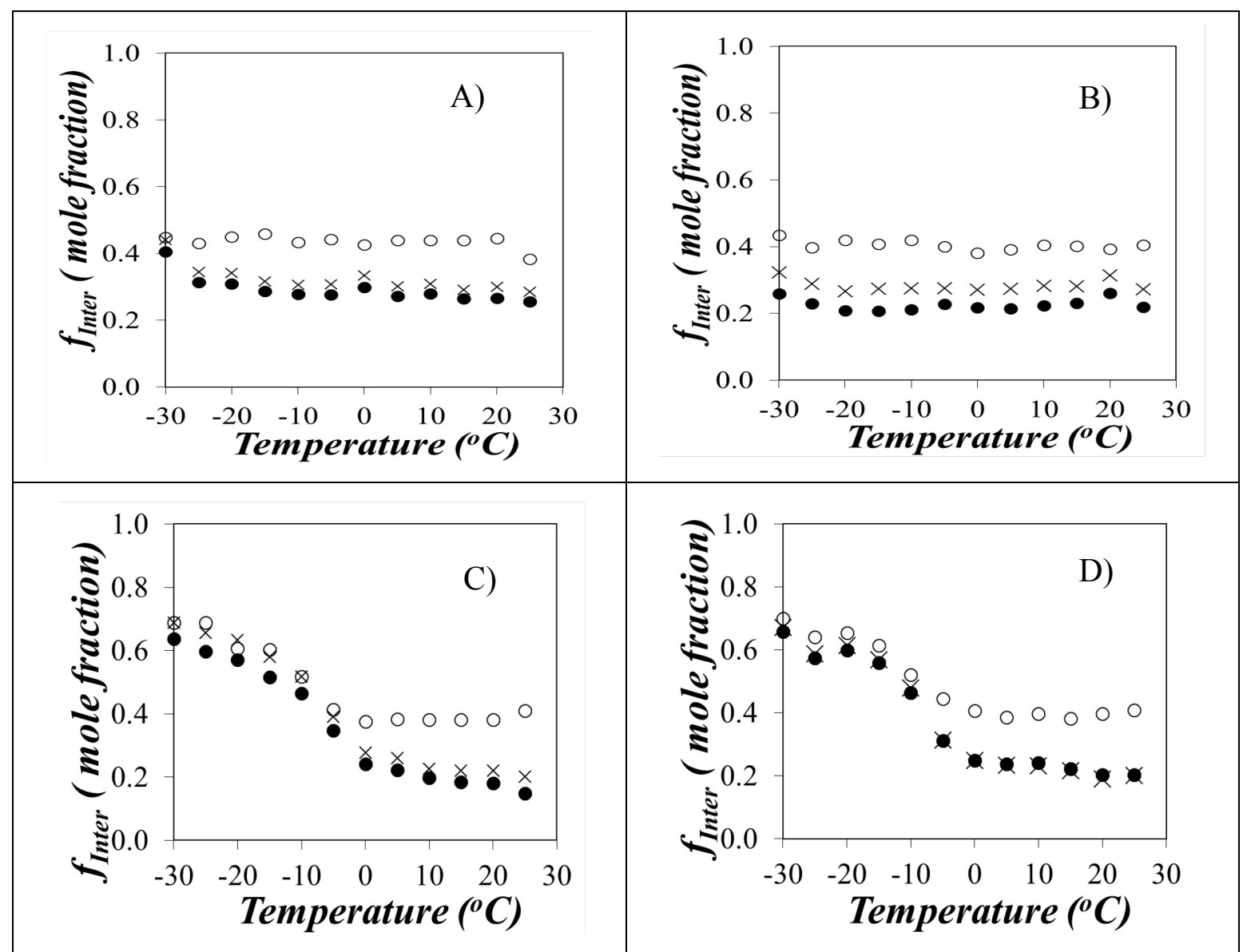

Figure 6. Molar fraction $f_{\text {inter }}$ of pyrene-labeled EP copolymers forming excimer intermolecularly calculated from the ratio $I_{\mathrm{E}}(500-530 \mathrm{~nm}) / I_{\mathrm{M}}(394-399 \mathrm{~nm})(\bullet)$ without wax and $(\bigcirc)$ with $10 \mathrm{~g} . \mathrm{L}^{-1}$ wax. $(\times)$ Molar fraction $f_{\text {inter }}$ calculated from the ratio $I_{\mathrm{E}}(500-530 \mathrm{~nm}) / I_{\mathrm{M}}(372-379 \mathrm{~nm})$ without wax. For A) Py(108)-EP(60-1), B) Py(103)-EP(61-2), C) Py(116)-EP(78-1), and D) Py(123)$\mathrm{EP}(78-3)$ at a concentration of 10 g. $\mathrm{L}^{-1}$. 


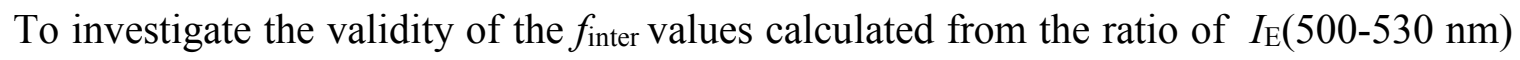
over $I_{\mathrm{M}}(394-399 \mathrm{~nm}), f_{\text {inter }}$ was also calculated by taking the ratio of $I_{\mathrm{E}}(500-530 \mathrm{~nm})$ over $I_{\mathrm{M}}(372-$ $379 \mathrm{~nm}$ ) for polymer solutions without wax. These alternative $f_{\text {inter }}$ values were plotted as a function of temperature in Figure 6. Despite the difference in the wavelength range to calculate $I_{\mathrm{M}}$, similar $f_{\text {inter-vs- }} T$ profiles were obtained. This result demonstrates that the new integration range used to calculate $I_{\mathrm{M}}$ did not affect much the trends for $f_{\text {inter. Not }}$ to be overlooked, the fact that similar $f_{\text {inter- }} v s-T$ trends were obtained for two different amorphous and two different semicrystalline EP copolymers attests of the robustness of the procedure. The implications of these results are now briefly discussed.

Table 4. Molar fraction $\left(f_{\text {inter }}\right)$ representing the intermolecular interactions between EP copolymer for 10 g. $\mathrm{L}^{-1}$ copolymer and 10 g. $\mathrm{L}^{-1}$ wax solutions in toluene.

\begin{tabular}{|c|c|c|c|c|}
\hline & \multicolumn{2}{|c|}{$\begin{array}{c}\text { Temp }\left({ }^{\circ} \mathrm{C}\right) \\
-30 \text { to }-10\end{array}$} & $\begin{array}{c}\text { Temp }\left({ }^{\circ} \mathrm{C}\right) \\
-5 \text { to } 25\end{array}$ & \multicolumn{2}{|c|}{$\begin{array}{c}\text { Temp }\left({ }^{\circ} \mathrm{C}\right) \\
-30 \text { to }-10\end{array}$} & $\begin{array}{c}\text { Temp }\left({ }^{\circ} \mathrm{C}\right) \\
-5 \text { to } 25\end{array}$ \\
\cline { 2 - 5 } & \multicolumn{2}{|c|}{ Without Wax } & \multicolumn{2}{|c|}{ With Wax } \\
\hline Py(108)-EP(60-1) & \multicolumn{2}{|c|}{$0.28 \pm 0.02$} & \multicolumn{2}{|c|}{$0.43 \pm 0.01$} \\
\hline Py(103)-EP(61-2) & \multicolumn{2}{|c|}{$0.22 \pm 0.02$} & \multicolumn{2}{|c|}{$0.40 \pm 0.01$} \\
\hline Py(116)-EP(78-1) & $0.56 \pm 0.07$ & $0.20 \pm 0.03$ & $0.57 \pm 0.07$ & $0.39 \pm 0.01$ \\
\hline Py(123)-EP(78-3) & $0.55 \pm 0.06$ & $0.23 \pm 0.02$ & $0.63 \pm 0.07$ & $0.39 \pm 0.01$ \\
\hline
\end{tabular}

Due to their importance in numerous applications that involve oil flow, the interactions of waxes and polymers have been the object of intensive research as illustrated by a number of recent reviews. ${ }^{34-36}$ Wax crystallization in the oil as stacked lamellar crystals leads to gelation of the oil that can no longer flow at a temperature referred to as the pour point (PP). Copolymers of ethylene and vinyl acetate, polyethylene- $b$-poly(ethylene-co-propylene) diblock copolymers (PE-PEP), or 
poly(maleic anhydride amide- $c o-\alpha-$ olefin) have been used as pour point depressants (PPDs). Their co-crystallization with waxes changes the size and shape of the wax crystals in a process that lowers the PP of the oil. In comparison with the vast pool of studies documenting the interactions between wax and PPDs, much less seems to be known about the interactions between waxes and VIIs such as the EP copolymers studied herein. In particular, interactions between waxes and EP copolymers having a high ethylene content were found to be reduced at low temperatures as illustrated in Figures 6C and D contrary to reported expectations. ${ }^{12}$ The suggestion that waxes do not co-crystallize with long polyethylene stretches of the EP(78) copolymers at low temperature is supported by studies of the interactions of waxes with PE-PEP. The diblock copolymers were found to self-assemble into platelets composed of the PE blocks stabilized by the amorphous PEP blocks. ${ }^{37}$ Addition of wax to the solution did not result in co-crystallization of wax and the PE blocks which formed PE-only microcystals. Rather, the wax crystallized at the surface of the PE platelet. ${ }^{38}$ The EP(78) samples seemed to behave similarly with their long polyethylene stretches forming microcrystals in a process that releases into the bulk the wax responsible for increasing intermolecular interactions at high temperatures above $T_{\mathrm{C}}$. As a result, the presence of wax did not increase intermolecular interactions of the $\mathrm{EP}(78)$ copolymers at low temperatures below $T_{\mathrm{C}}$ as indicated by the similar $f_{\text {inter }}$ value obtained with or without wax in Figure $6 \mathrm{C}$ and $\mathrm{D}$ and in Table 4. Both amorphous EP(60) copolymers consistently interacted with wax over the entire temperature range, maintaining a constant $f_{\text {inter }}$ value in the presence of wax that was larger than the $f_{\text {inter }}$ value obtained without wax.

Wax is believed to interact with long ethylene sequences in $\mathrm{EP}(60)$ and since the polymer remains fully soluble in toluene over the entire temperature range, these long ethylene sequences do not form microcrystals and interact effectively with wax in a process that induces intermolecular 
association. Interestingly, the semicrystalline EP copolymers were also found to interact strongly with wax at temperatures above $T_{\mathrm{C}}$ where they were fully soluble in toluene. In effect, amorphous and semicrystalline EP copolymers above $T_{\mathrm{C}}$ behaved similarly in solution, interacting strongly with wax in a process that resulted in increased intermolecular interactions.

\section{CONCLUSIONS}

Four EP copolymers were maleated and then labeled with 1-pyrenemethylamine. Two EP copolymers were semicrystalline and two were amorphous. ${ }^{19}$ To probe the interactions taking place between polymer chains in the presence of wax, fluorescence experiments based on pyrene excimer formation were conducted on the Py-EP copolymers. The Py-EP samples yielded very similar trends for the $I_{\mathrm{E}} / I_{\mathrm{M}}-\mathrm{vs}-T$ plots in the presence or absence of wax. While $I_{\mathrm{E}} / I_{\mathrm{M}}$ increased continuously with increasing temperature for Py(108)-EP(60-1) and Py(103)-EP(61-2), a much more complex profile was found for Py(116)-EP(78-1) and Py(123)-EP(78-2). As concluded earlier, ${ }^{19}$ this behaviour was due to the formation of microcrystals in solution that took place at low temperatures.

Application of Equation 2 to the $I_{\mathrm{E}} / I_{\mathrm{M}}$ profiles obtained with a 10 g.L $\mathrm{L}^{-1}$ Py-EP copolymer solution and a solution containing 0.01 g.L $\mathrm{L}^{-1}$ of Py-EP and 10 g.L $\mathrm{L}^{-1}$ of EP copolymer in the presence of 10 g.L $\mathrm{L}^{-1}$ of wax yielded $f_{\text {inter }}$, the molar fraction of pyrene labels that formed excimer intermolecularly when wax was added to toluene. Plots of $f_{\text {inter }}$ as a function of temperature for the two amorphous polymers, namely $\mathrm{Py}(108)-\mathrm{EP}(60-1)$ and $\mathrm{Py}(103)-\mathrm{EP}(61-2)$, showed that the presence of wax led to an increase in $f_{\text {inter }}$ from $0.28 \pm 0.02$ to $0.43 \pm 0.01$ and from $0.22 \pm 0.02$ to $0.40 \pm 0.01$, respectively. For the semicrystalline Py-EP solutions, two regimes were clearly identified depending on whether the solution temperature was below or above $T_{\mathrm{C}}$. The increase in 
$f_{\text {inter }}$ upon addition of 10 g. $\mathrm{L}^{-1}$ wax was more pronounced at temperatures higher than $T_{\mathrm{C}}$ where the semicrystalline EP copolymers did not form microcrystals. At lower temperatures, much smaller changes in $f_{\text {inter }}$ were observed. The presence of 10 g. $\mathrm{L}^{-1}$ wax in the EP solutions seemed to increase intermolecular associations between EP copolymers under solution conditions where no microcrystals could form $\left(T>T_{\mathrm{C}}\right)$. This observation suggests that the formation of polymer microcrystals at temperatures below $T_{\mathrm{C}}$ led to the release of wax from the polymers. It also supports the notion that wax interacts strongly with long ethylene sequences along the EP copolymer since wax would not be released into the bulk if it was binding to amorphous propylenerich sequences that are unaffected by microcrystal formation. As a result, the semicrystalline polymers at low temperatures showed little-to-no difference in behaviour with or without wax present in the solution.

In summary, this study illustrates how the parameter $f_{\text {inter }}$ can be used to probe the association between PyLMs in solution. In the present application, it was employed to probe the effect that wax present in engine oils has on the aggregation of VIIs. While this information is highly relevant to scientists aiming to control the viscosity of engine oils, the use of $f_{\text {inter }}$ based on PEF measurements conducted on PyLMs is general and is applicable to probe the solution behaviour of any associating polymers in organic solvents where the pyrene-labels are soluble.

\section{ACKNOWLEDGEMENTS}

The authors are thankful to Afton for generous funding. JD is indebted to Kiarash Gholami and Remi Casier for their help in the characterization of the wax. 


\section{SUPPORTING INFORMATION}

${ }^{13} \mathrm{C}$ NMR and FTIR spectra of EP copolymers, DSC traces, plots of $I_{\mathrm{E}} / I_{\mathrm{M}}$ ratios as a function of temperature, and GPC tracesand absorption spectrum of wax.

\section{REFERENCES}

1. Pawlak, Z. In Tribochemistry of Lubricating Oils; Elsevier: Poland, 2003; Vol. 45.

2. Zhang, M.; Duhamel, J. Study of the Microcrystallization of Ethylene-Propylene Random Copolymers in Solution by Fluorescence. Macromolecules 2007, 40, 661-669.

3. Rubin, I. D.; Sen, A. Solution Viscosities of Ethylene-Propylene Copolymers in Oils. J. Appl. Polym. Sci. 1990, 40, 523-530.

4. Sen, A.; Rubin, I. D. Molecular Structures and Solution Viscosities of Ethylene-Propylene Copolymers. Macromolecules 1990, 23, 2519-2524.

5. LaRiviere, D.; Asfour, A. A.; Hage, A.; Gao, J. Viscometric Properties of Viscosity Index Improvers in Lubricant Base Oil over a Wide Temperature Range. Part I: Group II Base Oil. Lubr. Sci. 2000, 12, 133-143.

6. Tanveer, S.; Prasad, R. Enhancement of Viscosity Index of Mineral Base Oils. Indian J. Chem. Technol. 2006, 13, 398-403.

7. Mihaljuš S. V.; Podobnik, M.; Bambić, J. Engine Oil Viscosity Index Improver Behaviour at Extended Shear Stability. Fuels Lubr. 2008, 47, 118-128.

8. Kucks, M. J.; Ou-Yang, H. D.; Rubin, I. D. Ethylene-Propylene Copolymer Aggregation in Selective Hydrocarbon Solvents. Macromolecules 1993, 26, 3846-3850.

9. Port, W. S.; O'Brien, J. W.; Hansen, J. E.; Swern, D. Viscosity Index Improvers for Lubricating Oils. Polyvinyl Esters of Long-Chain Fatty Acids. Ind. Eng. Chem. 1951, 43, 2105-2107.

10. Handlin, D. L.; Rhodos, R. B.; Stevens, C. A. Star Polymer Viscosity Index Improver for 
Lubricating Oil Compositions. UP 0700942A2, 1996.

11. Rudnik, L. R. In Chemistry and Application; Barbadsz, E. A.; Lamb, G. D. Eds.; Lubricant Additives; CRC Press, Boca Raton: Florida, 2003; pp 458-490.

12. Staumbaugh, R. L.; Kinder, B. G. Viscosity Index and Thickeners In Chemistry and Technology of Lubricants. Eds. Mortier, R. M.; Malcolm, F. F.; Orszulik, S. T., Springer: London, 2009, pp 158.

13. Simon, A. M.; Herbert, F. X-ray Fluorescence Detection of Waste Engine Oil Residue in Asphalt and its Effect on Cracking in Service. Int. J. Pav. Eng. 2010, 11, 541-553.

14. Castro, L. V.; Vazquez, F. Copolymers as Flow Improvers for Mexican Crude Oils. Energy Fuel. 2008, 22, 4006-4011.

15. Anghel, D. F.; Alderson, V.; Winnik, F. M.; Mizusaki, M.; Morishima, Y. Fluorescent Dyes as Model 'Hydrophobic Modifiers' of Polyelectrolytes: A Study of Poly(Acrylic Acid)s Labeled with Pyrenyl and Naphthyl Groups. Polymer 1998, 39, 3035-3044.

16. Yamamoto, H.; Mizusaki, M.; Yoda, K.; Morishima, Y. Fluorescence Studies of Hydrophobic Association of Random Copolymers of Sodium 2-(Acrylamido)-2-Methylpropanesulfonate and N-Dodecylmethacrylamide in Water. Macromolecules 1998, 31, 3588-3594.

17. Winnik, F. M.; Regismond, S. T. A. Fluorescence Methods in the Study of the Interactions of Surfactants with Polymers. Colloid Surf. A. Physicochem. Eng. Aspects 1996, 118, 1-39.

18. Jiang, S., Duggal, A., Duhamel, J., Pirouz, S. Quantifying the Level of Intermacromolecular Interactions by Using Pyrene Excimer Formation. USP 9354180, 2015

19. Pirouz, S.; Duhamel, J.; Jiang, S.; Duggal, A. Quantifying the Level of Intermacromolecular Interactions in Ethylene-Propylene Copolymers by Using Pyrene Excimer Formation. Macromolecules 2015, 48, 4620-4630. 
20. Vangani, V.; Drage, J.; Mehta, J.; Mathew, A. K.; Duhamel, J. Maleated Ethylene-Propylene Random Copolymers: Determination of the Microstructure and Association Level by Fluorescence Spectroscopy. J. Phys. Chem. B 2001, 105, 4827-4839.

21. Zhang, M.; Duhamel, J. Effect of Solvent Quality Toward the Association of Succinimide Pendants of a Modified Ethylene-Propylene Copolymer in Mixtures of Toluene and Hexane. Macromolecules 2005, 38, 4438-4446.

22. Zhang, M.; Duhamel, J. Study of Maleated Ethylene-Propylene Copolymers by Fluorescence: Evidence for Succinimide Induced Polar Associations in an Apolar Solvent. Eur. Polym. J. 2008, 44, 3005-3014.

23. Kim, S. D.; Torkelson, J. M. Nanoscale Confinement and Temperature Effects on Associative Polymers in Thin Films: Fluorescence Study of a Telechelic, Pyrene-Labeled Poly(Dimethylsiloxane). Macromolecules 2002, 35, 5943-5952.

24. Ingratta, M.; Duhamel, J. Correlating Pyrene Excimer Formation with Polymer Chain Dynamics in Solution. Possibilities and Limitations. Macromolecules 2007, 40, 6647-6657.

25. Randall, J. C. A Review of High Resolution Liquid Carbon Nuclear Magnetic Resonance Characterizations of Ethylene-Based Polymers. J. Macro. Sci. Rev. Macr. Chem. Phys. 1989, C29, 201-317.

26. Alshaiban, A.; Soares, J. B. P. Effect of Hydrogen and External Donor on Propylene Polymerization Kinetics with a 4th Generation Ziegler-Natta Catalyst. Macro. React. Eng. 2012, 6, 265-274.

27. API Base Oil Interchangeability Guidelines for Passenger Car Motor Oils and Diesel Engine Oils. American Petroleum Institute, API 1509, Appendix E, 2011.

28. Heinen, W.; Rosenmöller, C. H.; Wenzel, C. B.; De Groot, H. J. M..; Lugtenburg, J. 13C NMR 
Study of the Grafting of Maleic Anhydride onto Polyethene, Polypropene, and Ethene-Propene Copolymers. Macromolecules 1996, 29, 1151-1157.

29. Nemeth, S.; Jao, T.-C.; Fendler, J. H. Excimer Formation in 1-Pyrenyl-Methane-Amine Photochem. Photobiol. A: Chem. 1994, 78, 22-235.

30. Duhamel, J. Internal Dynamics of Dendritic Molecules Probed by Pyrene Excimer Formation. Polymers 2012, 4, 211-239.

31. Irondi, K.; Zhang, M.; Duhamel, J. Study of the Semidilute Solutions of Poly $(N, N-$ dimethylacrylamide) by Fluorescence and its Implications to the kinetics of Coil-to-Globule Transitions. J. Phys. Chem. B, 2006, 110, 2628-2637.

32. Farhangi, S.; Duhamel, J. Long Range Polymer Chain Dynamics Studied by Fluorescence Quenching. Invited Perspective to Macromolecules (accepted) 2016.

33. Duhamel, J. New Insights in the Study of Pyrene Excimer Fluorescence to Characterize Macromolecules and their Supramolecular Assemblies in Solution. Langmuir 2012, 28, 65276538.

34. Wei, B. Recent Advances on Mitigating Wax Problem Using Polymeric Wax Crystal Modifier. J. Petrol. Explor. Prod. Technol. 2015, 5, 391-401.

35. Radulescu, A.; Fetters, L. J.; Richter, D. Tailored Polymer Additives for Wax (Paraffin) Crystal Control. In Crude Oil Emulsions-Composition Stability and Composition. Eds El-Sayed Abdel-Raouf, M., InTech, Rijeka, Croatia, 2012, pp 205-230.

36. Radulescu, A.; Fetters, L. J.; Richter, D. Polymer-Driven Wax Crystal Control Using Partially Crystalline Polymeric Materials. Adv. Polym. Sci. 2008, 210, 1-100.

37. Richter, D.; Schneiders, D.; Monkenbush, M.; Willner, L.; Fetters, L. J.; Huang, J. S.; Lin, M.; Mortensen, K.; Farago, B. Polymer Aggregates with Crystalline Cores: The System 
Polyethylene-Poly(ethylenepropylene). Macromolecules 1997, 30, 1053-1068.

38. Leube, W.; Monkenbush, M.; Schneiders, D.; Richter, D.; Adamson, D.; Fetters, L.; Dounis, P.; Lovegrove, R. Wax-Crystal Modification for Fuel Oils by Self-Aggregating Partially Crystallizable Hydrocarbon Block Copolymers. Energy Fuels 2000, 14, 419-430.

Table of Content

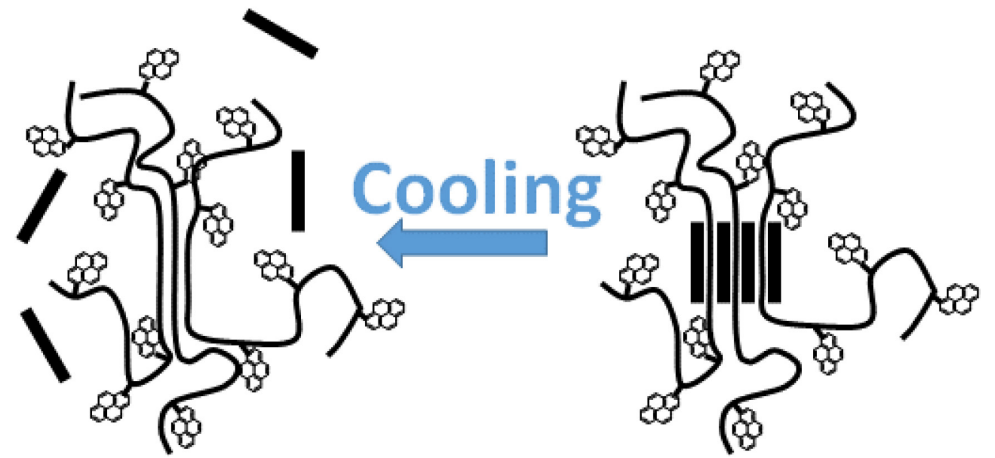

